\title{
Experimental Investigation of an Ammonia-Water-Hydrogen Diffusion Absorption Refrigerator
}

\author{
Ahmad Najjaran ${ }^{\mathrm{a}}$, James Freeman ${ }^{\mathrm{a}}$, Alba Ramos ${ }^{\mathrm{b}}$, Christos N. Markides $^{\mathrm{a}, *}$ \\ ${ }^{a}$ Department of Chemical Engineering, Imperial College London, \\ London, SW7 2AZ, United Kingdom \\ ${ }^{b}$ Polytechnic University of Catalonia/BarcelonaTech, Department of Engineering Presentation \\ (EGE), Barcelona School of Industrial Engineering (ETSEIB), Av. Diagonal 647, 08028 Barcelona, \\ Spain
}

\begin{abstract}
Diffusion absorption refrigeration (DAR) is a small-scale cooling technology that can be driven purely by thermal energy, such as renewable- or waste-heat, without the need for a mechanical compressor or circulation pump. DAR systems are of interest for cooling in off-grid communities and developing regions due to their electricity-free operation, low cost construction, and minimal requirement for maintenance or recharging. In this work, a detailed experimental evaluation was undertaken of a newly-proposed DAR unit with a nominal cooling capacity of $100 \mathrm{~W}$, aimed at solar-driven cooling applications. Electrical cartridge heaters were used to provide the thermal input which was varied in the range 150-700 $\mathrm{W}$, resulting in heat source temperatures of $175-215{ }^{\circ} \mathrm{C}$ measured at the generator. The cooling output during steady-state operation was determined indirectly from the power consumed by an electric heater used to maintain constant air temperature in an insulated box constructed around the evaporator. Tests were performed with the DAR system configured with the default manufacturer's settings (22 bar charge pressure and an ammonia concentration of $30 \%$ ). The measured cooling output across the range of generator heat inputs was $24-108 \mathrm{~W}$, while the coefficient of performance (COP) range was $0.11-0.26$. The maximum COP was obtained at a generator heat input of $300 \mathrm{~W}$. Results were compared to performance predictions from a steady-state thermodynamic model of the DAR cycle, showing a reasonable level of agreement at the nominal design point of system, but noteworthy deviations at part-load/off-design conditions. Temperature measurements from the experimental apparatus were used to evaluate assumptions used in the estimation of the model state point parameters and examine their influence on the predicted system performance.
\end{abstract}

Keywords: Diffusion absorption refrigeration, absorption cooling, ammonia-water, coefficient of performance, part-load operation 


\section{Nomenclature}

\section{Variables}

$\begin{array}{lll}c_{p} & \text { Specific heat capacity at constant pressure } & \mathrm{J} /(\mathrm{kgK})\end{array}$

$h \quad$ Specific enthalpy $\quad \mathrm{J} /(\mathrm{kg})$

$\dot{m} \quad$ Mass flow rate $\mathrm{kg} / \mathrm{s}$

$p \quad$ pressure bar

$\dot{Q} \quad$ Heat transfer rate $\quad$ W

T Temperature $\quad{ }^{\circ} \mathrm{C}$

$x \quad$ Molar fraction of liquid solution $\quad[-]$

y Ammonia mole fraction of vapour mixture $\quad[-]$

\section{Subscripts}

$\begin{array}{ll}\text { abs } & \text { Absorber } \\ \text { amb } & \text { Ambient } \\ \text { cond } & \text { Condenser } \\ \text { evap } & \text { Evaporator } \\ \text { gen } & \text { Generator } \\ \text { ig } & \text { Inert gas } \\ \text { loss } & \text { Thermal losses in the bubble pump } \\ \text { rect } & \text { Rectifier }\end{array}$

\section{Abbreviations}

COP Coefficient of performance

DAR Diffusion absorption refrigeration

GHX Gas heat exchanger

LHX Liquid solution heat exchanger

PIR Polyisocyanurate

\footnotetext{
*Author for correspondence

Email addresses: a.najjaran-kheirabadi16@imperial.ac.uk (Ahmad Najjaran), j.freeman12@imperial.ac.uk (James Freeman), alba.ramos@ies.upm.es (Alba Ramos), c.markides@imperial.ac.uk (Christos N. Markides)

$U R L:$ http://www.imperial.ac.uk/clean-energy-processes/ (Christos N. Markides)
} 


\section{Introduction}

Cooling represents $6.7 \%$ of current global energy consumption, approximately half of which is in the residential sector [1]. Global population increase and improved quality of life in emerging economies and warm climate regions will be likely drivers for further global cooling demand [2]. The current global space cooling sector is expected to double its capacity by 2025 due to the demand for electricity used for conventional vapour-compression refrigeration and air conditioning systems, with Asian countries becoming the dominant cooling energy consumers and western countries continuing to consume at their present rate. $[3,4]$. Conventional refrigerants can cause harm to the environment if released into the atmosphere due to their global warming and ozone depletion potentials. Alternative cooling technologies are of interest in order to mitigate the harmful emissions associated with conventional systems, and also to achieve a reduction in primary energy use from fossil fuels $[5,6]$ through the utilisation of renewable energy sources.

Cooling technologies can be categorised according to the type of input energy (e.g. solar, geothermal, and waste energy), or by the physical processes associated with the thermodynamic cycle (e.g. vapour compression, adsorption or absorption). Further categorisation can be made according to the cycle architecture, working fluid or sorption media. In adsorption cooling, latent heat is released when a refrigerant is adsorbed onto the surface of a solid medium. Optimal performance with a given heat source is dependent on the selection of suitable solid-fluid pairs [7-9]. Some of the most common adsorption solid-fluid couples are silica gel-water, activated carbon-ammonia and activated carbon-methanol $[10,11]$. More recently advanced zeolite materials have also shown favourable performance in combined adsorption cooling and desalination applications [12-14], while silica-salt composites have been proposed for novel lowtemperature adsorption heat-pumping applications in cold climate conditions [15].

Numerous thermally-driven refrigeration systems based on ejectors have been proposed and studied in the literature. A typical configuration uses low-grade heat to produce saturated vapour refrigerant at high pressure in the generator, which then passes through the primary nozzle of the ejector. The entrainment of secondary flow from the evaporator establishes the low-pressure condition for the low-temperature evaporation process, delivering cooling. Common limitations of ejector systems, as noted in Refs. [16-19], arise from poor performance at off-design conditions and large heat-exchanger 
area requirements. Furthermore, some ejector systems work in supersonic conditions which can cause unwanted noise and require specific safety measures. Nonetheless, certain configurations of the technology have proved viable in HVAC applications, with reported systems currently operational in offices and hospitals [20].

Absorption refrigeration is the most common sub-category of thermally-driven cooling encountered in the literature and on the market, and encompasses a wide range of technologies, both in terms cooling capacity and cycle configuration [21]. The main characteristic of absorption systems is that the vapourised refrigerant leaving the evaporator is returned to the liquid phase via absorption into a liquid solution with a less volatile component (the absorbent). Thermal energy (often from renewable or waste-heat sources) is supplied to separate the refrigerant from the absorbent by boiling it out of solution. The pure refrigerant is then condensed before being supplied as a liquid for the evaporation process [22-26].

The diffusion absorption refrigeration cycle (DAR) is a variant of the absorption cycle which has distinct advantages for small-scale applications in off-grid areas [27]. The DAR is a "single pressure" cycle in which the fluid circulation is driven by a thermally-powered bubble pump, thus any necessity for electrical or mechanical energy input can be omitted. As well as the refrigerant-absorbent fluid pair (usually ammoniawater), DAR systems also use a third fluid component: a low density inert gas such as hydrogen or helium that aids evaporation of the refrigerant by lowering its partial pressure in the evaporator. The DAR cycle was first devised by Von Platen and Munters in the 1920s [28] in order to meet the requirement for a low-cost domestic unit, and to address the problem of circulating the ammonia refrigerant without the need for a mechanically-driven pump or compressor. Prior to this, early absorption systems had used a liquid pump to raise the working fluid from the evaporation to the condensation pressure. Historically, DAR systems have been used in small, compact applications such as hotel minibar refrigerators, usually with a small electrical heater as the heat source. In addition to the electricity-free operation, further advantages of the system are low noise levels due to the absence of moving parts, low construction and maintenance costs, and the ability to manufacture as a one-piece unit which results in long operational lifetimes without the need for recharging [29-31]. However, DAR systems typically have a low coefficient of performance (COP) in comparison with other absorption cooling technologies; while the standard system requires heat source temperatures in the range of $140-200{ }^{\circ} \mathrm{C}$ when ammonia-water-hydrogen is used as the working fluid 
mixture [32-34]. This has led more recently to the consideration of alternative working fluid mixtures for lower temperature heat sources [35].

Previous investigations into the ammonia-water-hydrogen DAR cycle have included both experimental and numerical modelling efforts. Mazouz et al. [36] performed an experimental analysis of a small capacity DAR unit ( $\sim 20 \mathrm{~W}$ cooling) over a generator heat input range between 40-70 W. A COP between 0.07-0.12 was reported, with optimal performance corresponding to a heat input temperature of $185{ }^{\circ} \mathrm{C}$. Zohar et al. developed a numerical model of a DAR cycle and used it to simulate the performance of the system at various rich-solution concentrations of and to compare hydrogen and helium as the auxiliary gas. An ammonia mass fraction of between 0.25 0.3 was found to be optimal, while helium was found to offer an increase in COP of up to $40 \%$ compared to hydrogen. The predicted COP was between 0.13 and 0.31 , with the highest values predicted for higher evaporator temperatures. In a later work [37], the same authors used their DAR model to assess common organic refrigerants (R22, R32, R124, R125 and R134a) paired with the organic absorbent dimethylacetamide (DMAC) as the working fluid mixture, and helium as the inert gas. The alternative mixtures showed no advantages in terms of COP, and while some provided a slightly lower optimum generator temperature, the required condensation temperature was also lower, limiting their potential to operate in high ambient temperature conditions.

Other working fluid mixtures have also been investigated based on inorganic salt absorbents. Acuna et al. [38] used a numerical modelling approach to investigate sodium thiocyanate $(\mathrm{NaSCN})$ and lithium nitrate $\left(\mathrm{LiNO}_{3}\right)$ as alternative absorbents in combination with ammonia as the refrigerant and helium as the auxiliary gas. Both absorbents were predicted to give a higher COP than water at lower generator temperatures, with $\mathrm{LiNO}_{3}$ showing the highest COP of 0.48 at a generator temperature of $120{ }^{\circ} \mathrm{C}$. NaSCN was later investigated experimentally by Rattner and Garimella [3941], with a novel bubble pump configuration featuring a co-flow heat source fluid channel to achieve a higher generator heat transfer area and thus enabling lower heat source temperatures. A COP of up to 0.14 was achieved at evaporator temperatures representative of air-conditioning applications $\left(8-12{ }^{\circ} \mathrm{C}\right)$.

A number of previous studies focused on the components and geometry of DAR systems. Zohar et al. [42] modelled the influence of the heat exchanger in which liquid ammonia is subcooled prior to the evaporator inlet, and found that the subcooling of the refrigerant reduces the system COP by consuming some of the available cooling en- 
ergy at the evaporator, but also allows the system to provide significantly lower cooling delivery temperatures. In a later paper [43], the same authors investigated the configuration of the DAR bubble pump heat exchanger. In the standard configuration, heat is supplied through the weak solution in the outer shell of the heat exchanger to boil the rich solution in the inner tube. By separating the inner tube and outer shell at this location and supplying heat directly to the rich solution, a performance improvement of between 20-30 \% was predicted. Vicatos and Bennett [44] proposed a bubble pump design with multiple lift tubes in parallel to be tailored to the requirements of the heat source, and provided experimental results to show that a near-linear increase in mass flow-rate with heat load could be achieved by increasing the number of lift tubes from 1 to 3, without a significant reduction in COP of the system. A parallel-tube bubble pump configuration was also considered for an experimental system by Jakob et al. [45] in order to achieve a larger cooling capacity of up to $2.5 \mathrm{~kW}$. The parallel tubes were designed as coaxial heat exchangers with heat input from a heat transfer fluid flowing in the outer shell. Three prototype systems were tested and a maximum COP of 0.38 was achieved for a relatively high evaporator temperature of $15 / 18{ }^{\circ} \mathrm{C}$.

In this paper, a detailed experimental evaluation is conducted of a newly-proposed, domestic-scale ammonia-water-hydrogen DAR unit with a nominal cooling capacity of $100 \mathrm{~W}$, aimed specifically at solar-cooling applications. The experimental results are complemented by predictions from a model of this system in order to obtain an understanding of the operation and performance of DAR system, especially at offdesign conditions that are of great importance in solar applications, and to explore the predictive power of the model over the range of investigated conditions. The apparatus is presented in Section 2, along with a description of the thermodynamic processes that form the basis of the steady-state thermodynamic model of the system. The experimental results are presented in Section 3, where the main objective is to map the cooling capacity and COP of the system over the operating range of the system, relating specifically to the generator temperature and thermal input power; and to determine the optimal operating point of the DAR under the default manufacturer's settings (with regard to the working fluid mixture concentration and system pressure). The identification of the optimal operating point allows the system to be investigated further using a representative steady-state model, and in the second part of Section 3 the experimental results will be compared with simulations using the steady state system model configured with a range of suitable input assumptions. Finally, the main conclusions from this study are presented in Section 4. 


\section{Methodology}

\subsection{DAR cycle description}

A diagram of the ammonia-water DAR system is shown in Fig. 1, with the major components labelled. In the generator, the refrigerant-rich solution is heated (1-2) forming vapour bubbles that rise upwards, lifting liquid solution to the top of the bubble pump. The liquid and vapour phases are separated at the top of the bubble pump; the liquid solution (3) descends downwards in the outer shell of the bubble pump towards the absorber, while the saturated vapour mixture (4) proceeds upwards to the rectifier. The function of the rectifier is to remove any residual water from the vapour mixture by partial condensation. The liquid condensate exits from the bottom of the rectifier (5), while near-pure vapour refrigerant continues upwards to the condenser where it is condensed, releasing heat to the surroundings (6-7). The liquid refrigerant leaving the condenser is pre-cooled in the gas heat exchanger (7-9) before entering the evaporator, which is loaded with an inert gas (in this case, hydrogen). On entering the hydrogen environment, the refrigerant's partial pressure drops, and low-temperature evaporation occurs (9-10), producing the refrigeration effect. The refrigerant vapour and inert gas mixture then enter the absorber where the refrigerant (10) is absorbed into the weak solution (8) releasing heat to the surroundings and resulting in a refrigerantrich solution that is collected in the reservoir (11). The inert gas is not absorbed and, being less dense the refrigerant, rises back to the evaporator in the gas heat exchanger.

\subsection{Experimental apparatus}

The experimental DAR system is a single-piece unit constructed from steel tubing with welded connections, and has a nominal cooling output of $100 \mathrm{~W}$. For the experiments presented in this paper, the system was charged with ammonia-water solution at an overall mass-concentration of $30 \%$ and pressurised with hydrogen to 22 bar, as per the manufacturer's default specification. A photograph of the experimental system is shown in Fig. 2.

The DAR generator heat exchanger is a two-piece aluminium block with holes along the bottom edge, into which five cartridge heaters $(3 / 8 \times 4 \mathrm{in}, 350 \mathrm{~W}, 220 \mathrm{~V})$ were inserted (see Fig. 3). The heat exchanger block also contains four small heat pipes for improved heat conduction to the generator. The two halves of the heat exchanger 


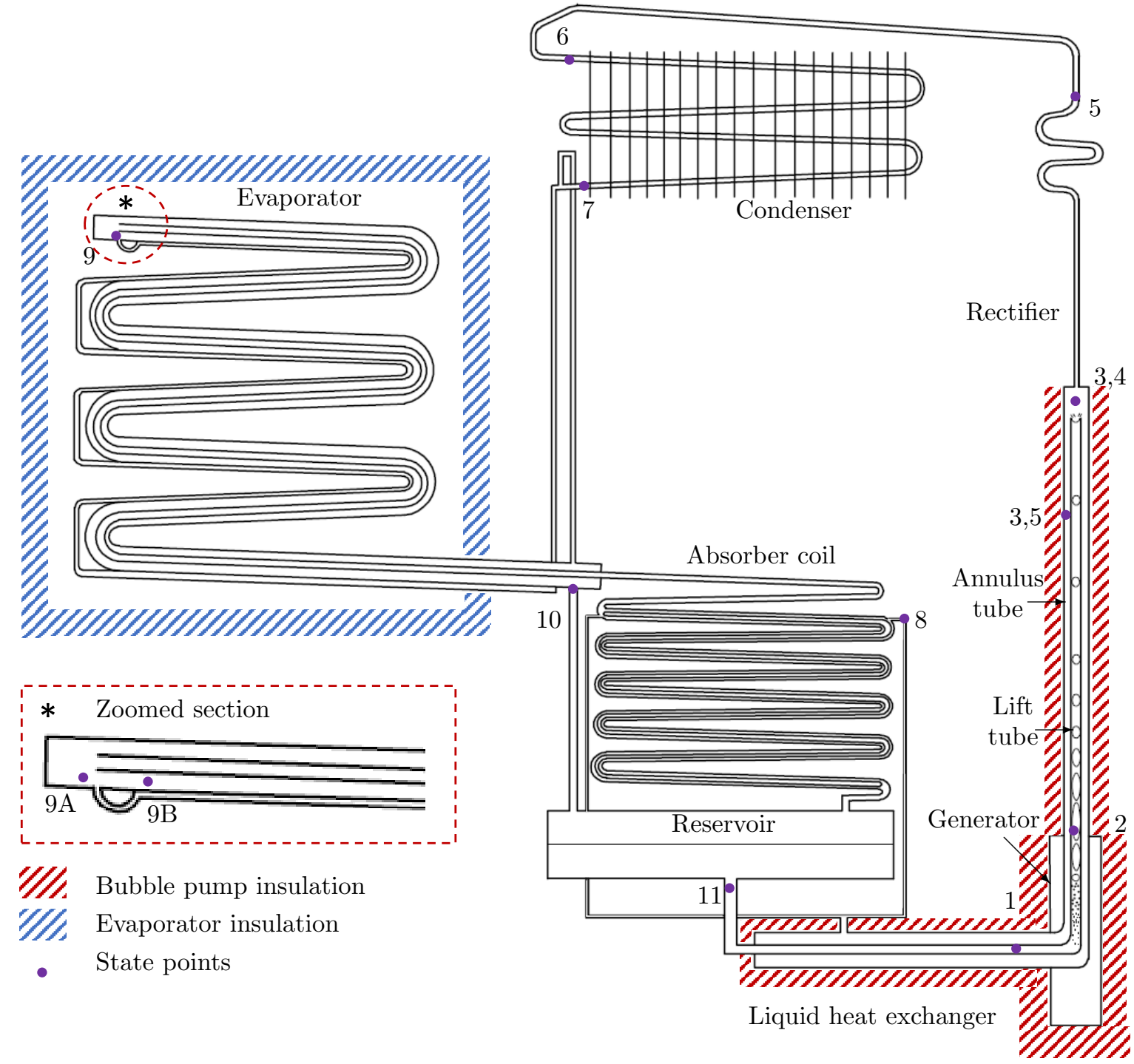

Figure 1. Diagram of the ammonia-water DAR system, with numbered state points indicating the processes described in Section 2.1. The zoomed-in section in the bottom left shows the mixing section where the refrigerant meets the inert gas at the top of the evaporator. block were clamped around the DAR generator pipe, and a thermally conductive paste was used to ensure a good thermal contact. The bubble pump was also insulated using $50 \mathrm{~mm}$ rock-wool pipe insulation. The heat exchanger block was insulated using several layers of mineral-fibre insulation and an outer casing of $75 \mathrm{~mm}$ rigid polyisocyanurate (PIR) insulation boards. A variable AC auto-transformer (variac) was used to adjust 173 the electrical power supplied to the cartridge heaters, and thus, also the heat supplied to 


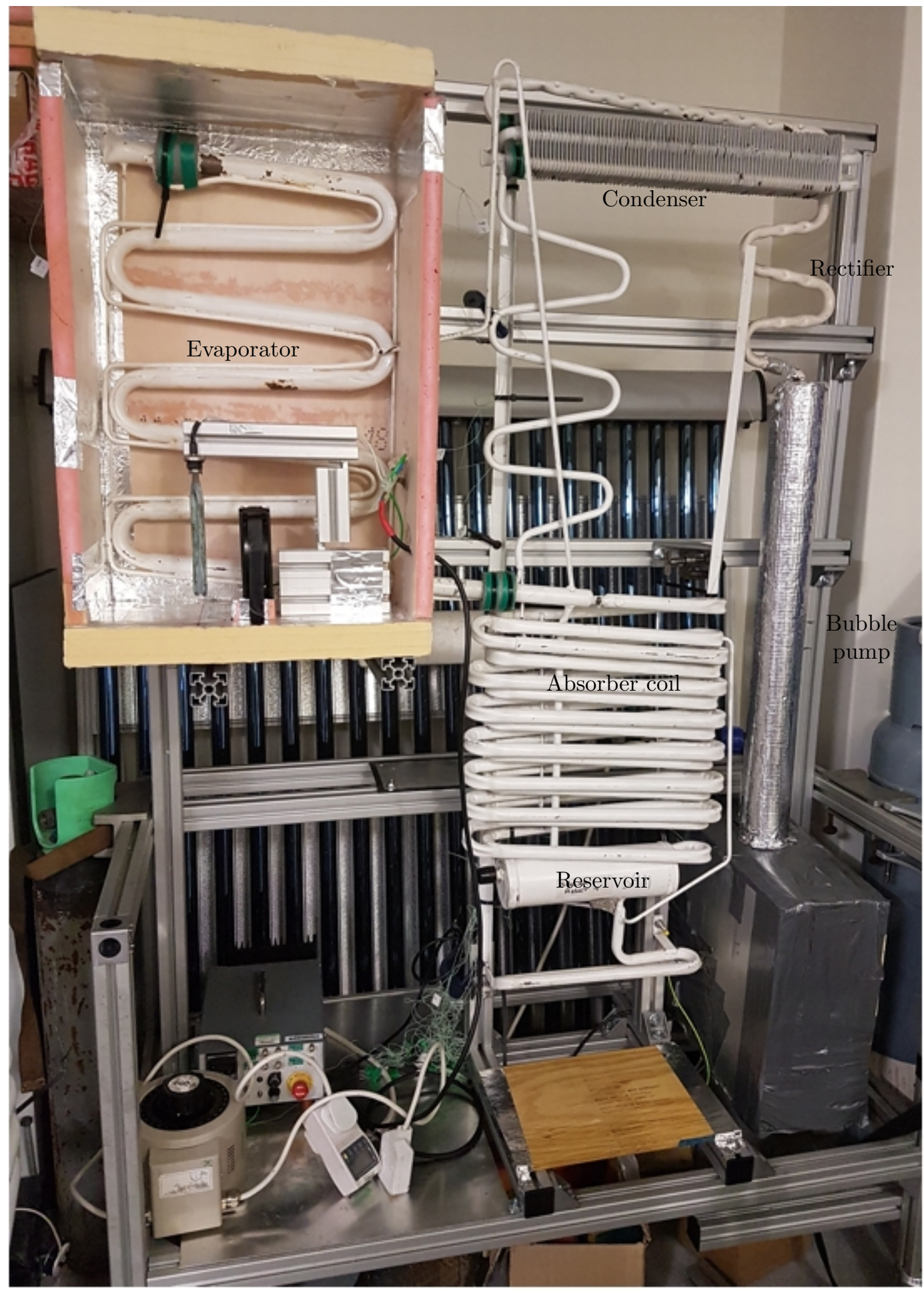

Figure 2. Photograph of the laboratory DAR system used in the experiments. 


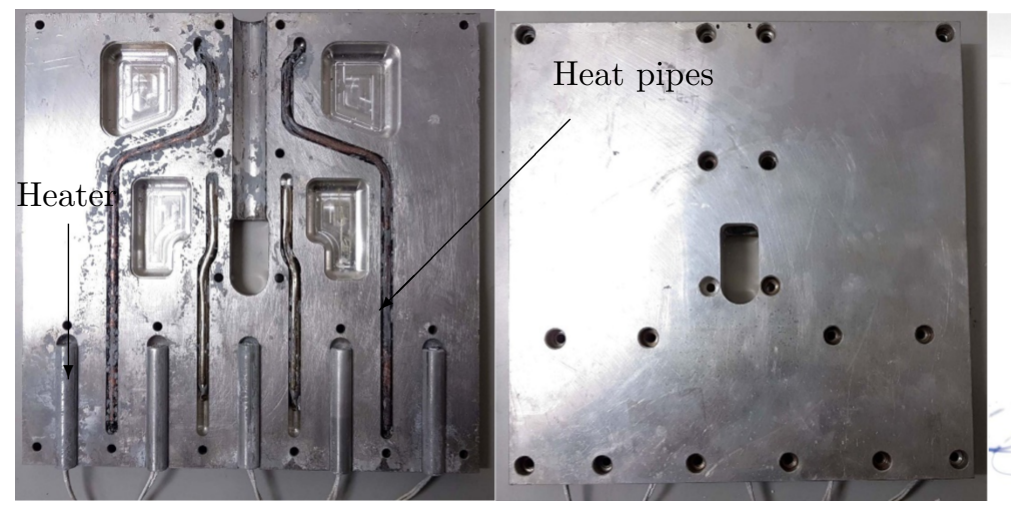

(a)

(b)

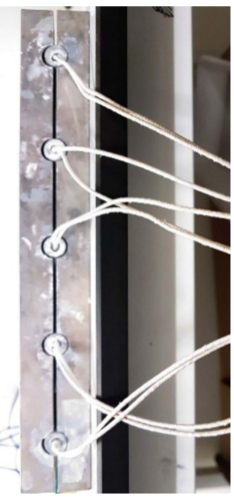

(c)

Figure 3. Photographs of the generator heat exchanger: a) internal view showing the slots for the generator pipe, heat pipes and cartridge heaters; b) external view showing the rear side with bolt holes c) bottom view showing cartridge heaters inserted into the slots.

the generator. The electrical power consumption of the cartridge heaters was measured using a Rohde and Schwarz HM-8115 digital power-meter with stated accuracy in active power measurement mode of $\pm 0.8 \%$.

An insulated box was constructed around the evaporator, made from PIR insulation boards with a thickness of $30 \mathrm{~mm}$ and a thermal conductivity of $0.022 \mathrm{~W} /(\mathrm{m} \cdot \mathrm{K})$. The internal dimensions of the cold box were $800 \times 450 \times 200 \mathrm{~mm}$. An electric fan-heater was used to maintain a constant air temperature of $\sim 25{ }^{\circ} \mathrm{C}$ inside the box during the experiments. The fan heater's output was controlled using a PID controller with feedback from a thermocouple inside the refrigerated space. The power consumption of the fan heater was measured using a second digital power meter: a Rohde and Schwartz HMC-8015 with a stated accuracy over the measurement range of $\pm 0.1 \%$. The cooling output from the DAR evaporator was assumed to be equal to the power consumed by the fan heater to maintain the air temperature inside the box.

In order to achieve a uniform temperature in the chilled space, two configurations were considered for the positioning of the heater and fan inside the enclosure, each resulting in a different air-circulation pattern. The chosen configuration was the one resulting in the most even air temperature distribution, in which the heater was situated at the bottom of the box and the air directed upwards across the front surface of the 
evaporator (see Fig. 4a). The fan speed was set to a sufficiently high value so that the air-side surface resistance did not dominate the cooling output from the evaporator. The appropriate setting was determined by steadily increasing the fan speed until no further increase in the cooling output was observed. The electrical power consumption of the circulation fan was found to be approximately $7 \mathrm{~W}$ during the tests, and this was added to the electrical consumption of the heater in order to determine the cooling output from the DAR system.

Temperatures were measured at various locations in the DAR system using K-type thermocouples (manufacturer-stated accuracy $\pm 1.5^{\circ} \mathrm{C}$ ) and logged to a computer by a data logger (manufacturer-stated accuracy $\pm 0.5-0.9{ }^{\circ} \mathrm{C}$, depending on the temperature reading; lower at lower temperatures). Where possible, these locations were chosen to represent the state points of the thermodynamic model of the DAR cycle (see Section 2.3). Due to the difficulty in measuring fluid temperatures directly, which would involve cutting into the system pipework, thermocouples were instead placed in contact with the outer surface of the steel tubes. A conductive paste was used to achieve a good thermal contact and improve the accuracy of the measurement.

The DAR system pressure was also not measured directly during the tests, but was estimated from the dew-point temperature of the near-pure ammonia observed in the condenser (see Section 3.1). Temperature profiles along the condenser and rectifier tubing were measured using regularly spaced thermocouples, as shown in Fig. 5, to obtain the dew-point temperature reliably.

In this work, each reported experimental parameter that defines each DAR working condition (i.e., generator power, evaporator/cooling power, temperatures) is an average of 200 independents measurement samples. Based on measured standard deviations, we estimate the statistical error in the mean reported values amounts to $<1 \%$ for the generator power, between $<1 \%$ and $10 \%$ for the evaporator/cooling power, at a $95 \%$ confidence interval. The worst case error in the mean for the reported temperatures was observed for the evaporator outlet thermocouple $\left(T_{10}\right)$, and amounted to $\pm 2{ }^{\circ} \mathrm{C}$.

\subsection{DAR system thermodynamic model}

A simple thermodynamic model of the DAR cycle is used to analyse the experimental results. In this section, a description of the main energy balance equations is provided with the numbered state points corresponding to those indicated in Fig. 1. For the full 


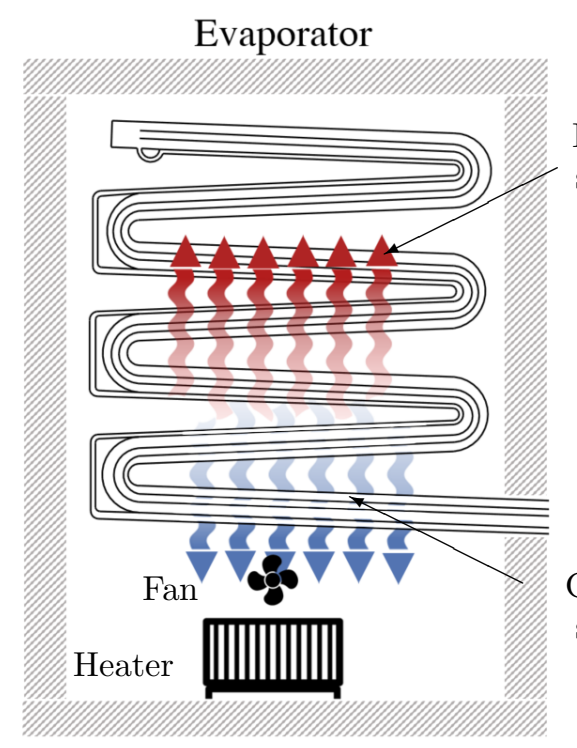

(a)

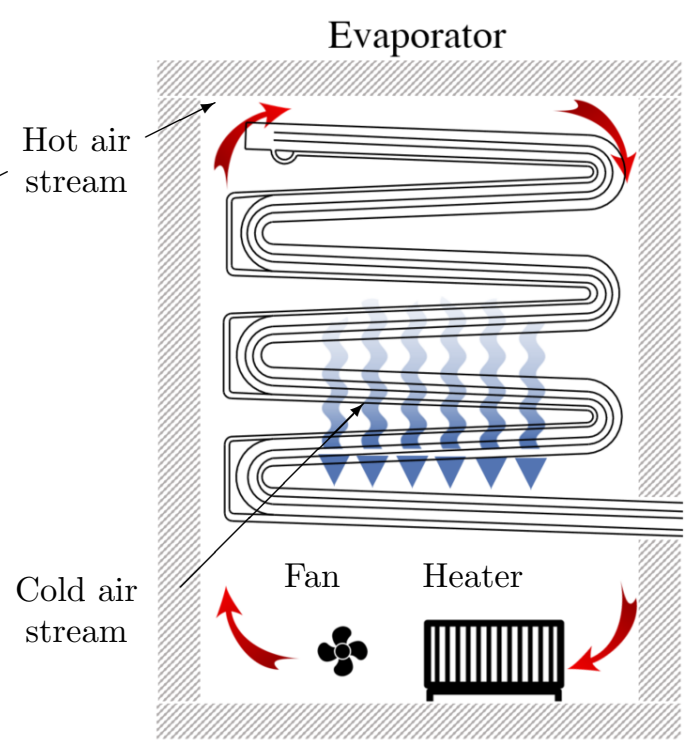

(b)

Figure 4. Configuration of the insulated enclosure constructed around the evaporator, showing alternative positioning arrangements for the electrical heater and fan.

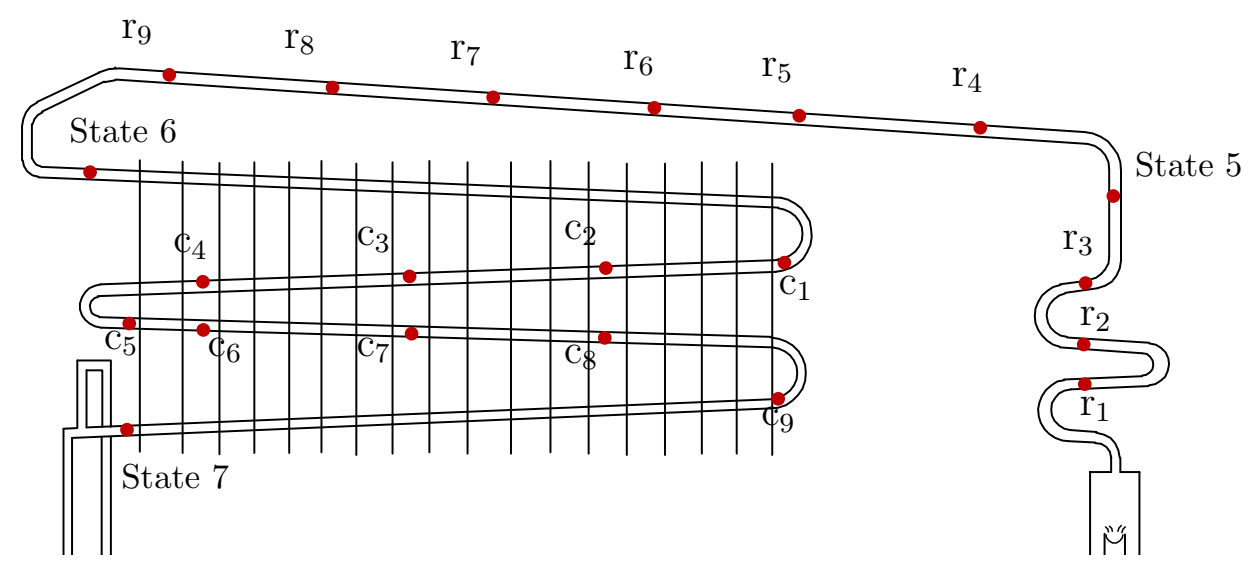

Figure 5. Thermocouple positioning along the rectifier (denoted r) and condenser (denoted $\mathrm{c})$.

list of equations used in the model, the reader is referred to the prior work by Starace and De Pascalis [46]. 
Equation 1 is the energy balance for the generator and bubble pump. The net enthalpy rise of the ammonia-water mixture in the generator/bubble pump is equal to the heat supplied $\left(\dot{Q}_{\text {gen }}\right)$ minus the heat dissipated to the surroundings $\left(\dot{Q}_{\text {loss }}\right)$. It is assumed that State 1 is a saturated liquid, while vapour-liquid equilibrium is assumed between State 3 (liquid) and State 4 (vapour). For a case in which it is assumed that the bubble pump and the generator are perfectly insulated, the heat dissipation term is neglected and temperatures $T_{2}=T_{3}=T_{4}$.

$$
\dot{Q}_{\text {gen }}-\dot{Q}_{\text {loss }}=\dot{m}_{3} h_{3}+\dot{m}_{4} h_{4}-\dot{m}_{1} h_{1}
$$

Equation 2 is the energy balance for the rectifier. $\dot{Q}_{\text {rect }}$ is the heat rejected to the surroundings by the partial condensation of the water fraction from the vapour mixture. Vapour-liquid equilibrium is assumed between the entering vapour mixture (State 4) and the exiting condensate (State 5). State 6 is the near-pure ammonia proceeding to the condenser.

$$
\dot{Q}_{\text {rect }}=\dot{m}_{5} h_{5}+\dot{m}_{6} h_{6}-\dot{m}_{4} h_{4}
$$

Equation 3 is the energy balance for the condenser. $\dot{Q}_{\text {cond }}$ is the heat rejected to the surroundings by the condensation of the ammonia refrigerant (and any remaining water fraction) at the system condensation pressure.

$$
\dot{Q}_{\text {cond }}=\dot{m}_{6}\left(h_{7}-h_{6}\right) \text {. }
$$

The liquid refrigerant flow-rate proceeding to the evaporator is assumed equal to that leaving the condenser, $\dot{m}_{6}=\dot{m}_{7}=\dot{m}_{9}$. In Eq. 4 the energy balance for the evaporator considers both the pre-cooling and evaporation processes and also the massflows of refrigerant and inert gas (ig). By assuming a saturated vapour at the evaporator outlet (State 10), the partial pressures and mass fractions of refrigerant and inert gas are determined from the saturated vapour temperature.

$$
\dot{Q}_{\text {evap }}=\dot{m}_{9}\left(h_{10}-h_{7}\right)+\dot{m}_{\text {ig }}\left(h_{10, \mathrm{ig}}-h_{8, \mathrm{ig}}\right) .
$$


In the absorber energy balance (Eq. 5), refrigerant vapour mixed with inert gas is introduced from the bottom (State 10) via the reservoir, while the weak solution is introduced at the top (State 8). The refrigerant is absorbed into the weak solution, releasing heat to the surroundings $\left(\dot{Q}_{\text {abs }}\right)$, and the remaining inert gas exits at the top of the absorber. It is assumed that the inert gas exits at the same temperature as the weak solution that is introduced, $T_{8}=T_{8, i g}$.

$$
\dot{Q}_{\mathrm{abs}}=\dot{m}_{11} h_{11}-\dot{m}_{10} h_{10}-\dot{m}_{8} h_{8}+\dot{m}_{\mathrm{ig}}\left(h_{8, \mathrm{ig}}-h_{10, i g}\right) .
$$

Equation 5 is the energy balance for the liquid solution heat exchanger. Thermal energy is transferred from the refrigerant-weak solution flowing in the outer annulus to the refrigerant-rich solution in the inner tube. It is assumed in the model that no heat losses occur to the surroundings.

$$
\dot{m}_{3} h_{3}+\dot{m}_{5} h_{5}-\dot{m}_{8} h_{8}=\dot{m}_{1}\left(h_{1}-h_{11}\right)
$$

In Equations 1-6, the molar concentrations and specific enthalpies of the ammoniawater mixture under vapour-liquid equilibrium conditions are evaluated using the empirical functions of Patek and Klomfar [47]. Finally, in Eq. 7, the coefficient of performance $(\mathrm{COP})$ is the ratio of the cooling output power at the evaporator to the heat input at the generator:

$$
\mathrm{COP}=\frac{\dot{Q}_{\text {evap }}}{\dot{Q}_{\text {gen }}}
$$

\subsection{Model inputs and assumptions}

The DAR system model requires the specification of a number of input parameters, specifically the generator heat input rate $\dot{Q}_{\text {gen }}$, total system pressure $p_{\text {tot }}$, and the temperatures $T_{1}, T_{2}, T_{6}$, and $T_{10}$. Based on these inputs, the outputs from the model are the system flow-rates and remaining state-point temperatures, the cooling capacity $\dot{Q}_{\text {evap }}$, and thus also the system COP. In the present study, $\dot{Q}_{\text {gen }}$, and most of the temperature input parameters were provided using direct measurements from the experiments, while $p_{\text {tot }}$ was determined indirectly from the saturation temperature measured along 
the rectifier and condenser section (see Section 3.1).

The precise values of $T_{1}$ and $T_{2}$ could not be verified accurately in the experiments, due to the difficulty of obtaining a temperature measurement of the rich solution flow in the inner tube of the generator. Thus at State 1 the temperature was estimated as the saturated liquid temperature corresponding to an ammonia concentration of $x_{1}=0.3$; while for State 2 a temperature difference of $2 \mathrm{~K}$ was assumed between the flow in the inner tube and the measured temperature at the outer tube (this assumption was also used in the DAR system model by Zohar et al. [48]).

In the work by Starace and De Pascalis [46] on which the thermodynamic model in the present work is based, the following assumptions were used to solve the model equations:

1. No sub-cooling occurs in the condenser, hence the fluid exiting at State 7 is a saturated liquid;

2. Refrigerant leaves the evaporator at State 10 as a saturated vapour;

3. The temperature exiting the condenser is equal to the reservoir temperature: $T_{7}$ $=T_{11}$;

4. No thermal losses occur to ambient in the liquid solution heat exchanger.

The experimental results in this study will be used to evaluate the above assumptions and assess their impact on the prediction of the system performance.

\section{Results and discussion}

\subsection{Experimental observations}

The experimental measurements of the DAR system cooling capacity over the investigated range of generator heat input rates are plotted in Fig. 6. For these measurements, the chilled space temperature was maintained at $25{ }^{\circ} \mathrm{C} \pm 1{ }^{\circ} \mathrm{C}$. From Fig. 6 it can be observed that the cooling output from the system increases as the generator heat input is raised from $150 \mathrm{~W}$ to $400 \mathrm{~W}$, after which there is a plateau at a maximum value of $103 \mathrm{~W} \pm 5 \mathrm{~W}$, followed by an eventual decrease in cooling output at $\dot{Q}_{\text {values }}>650 \mathrm{~W}$.

The COP of the system, also shown in Fig. 6, is calculated based on the measured generator heat input and cooling output. The COP is shown to reach a peak value of 


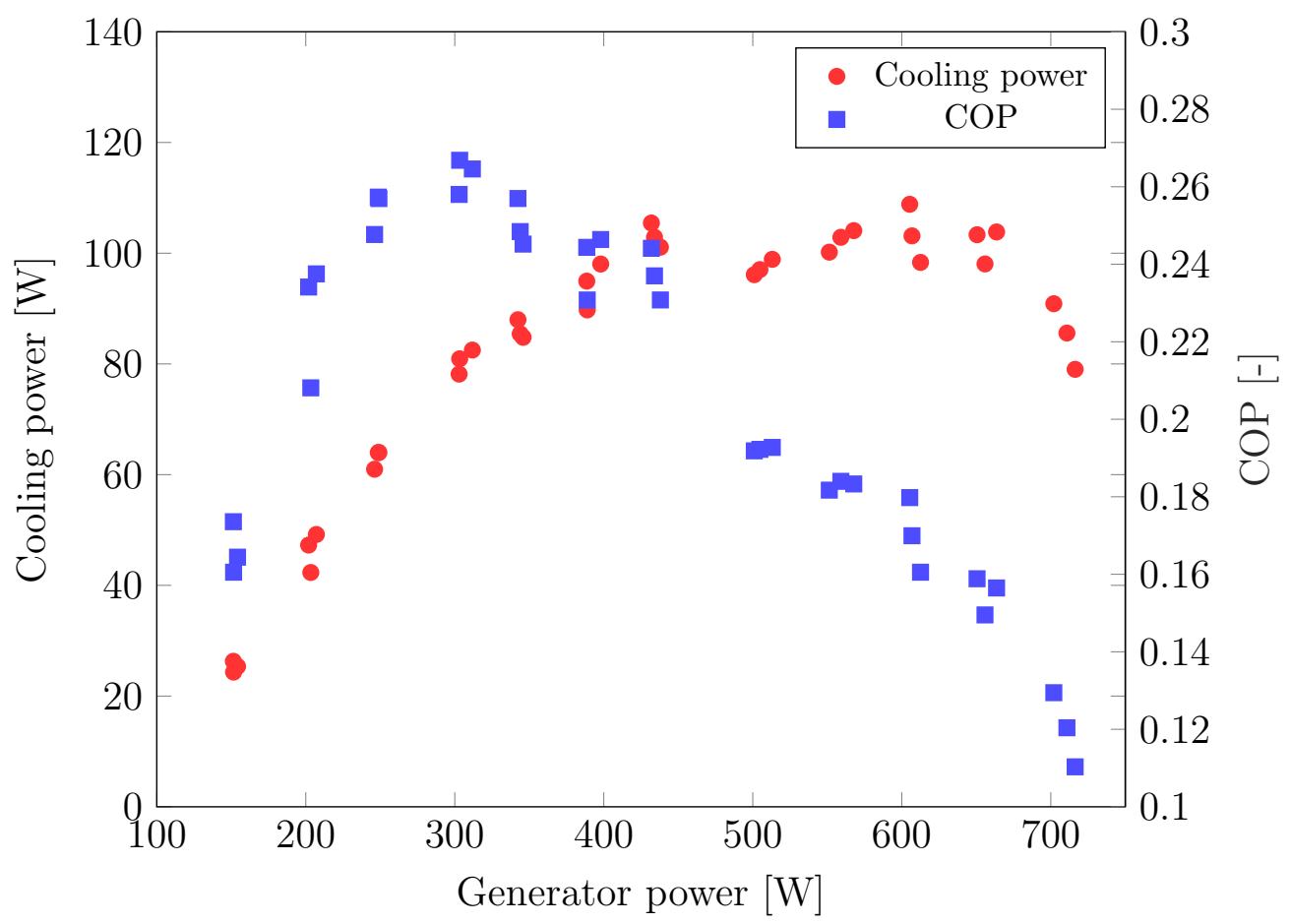

Figure 6. Experimental DAR system cooling capacity and coefficient of performance (COP) plotted against generator heat input.

0.26 at a generator heat input of $300 \mathrm{~W}$. A likely hypothesis is that this corresponds to the operating condition at which the maximum flow-rate of ammonia refrigerant vapour is delivered from the rectifier to the condenser, with a minimal fraction of water vapour. At higher values of $\dot{Q}_{\text {gen }}$, insufficient heat is rejected in the rectifier to condense out the water vapour, and thus a progressively higher water vapour fraction is carried over to the condenser and the evaporator (as evidenced by the increase in temperature measured at the condenser inlet), limiting the achievable specific cooling output. At lower values of $\dot{Q}_{\text {gen }}$, excessive heat is rejected in the rectifier which also results in some unwanted condensation of the ammonia fraction, and thus a lower flowrate of refrigerant delivered to the condenser and evaporator, also limiting the cooling output. In Fig. 7 the cooling output and COP are plotted against the generator (heat source) temperature. It can be observed that the maximum cooling output corresponds to a generator temperature in the range $180-210{ }^{\circ} \mathrm{C}$, with a higher COP occurring at the lower end of this temperature range.

As stated in the previous section, the system pressure is not measured directly in 


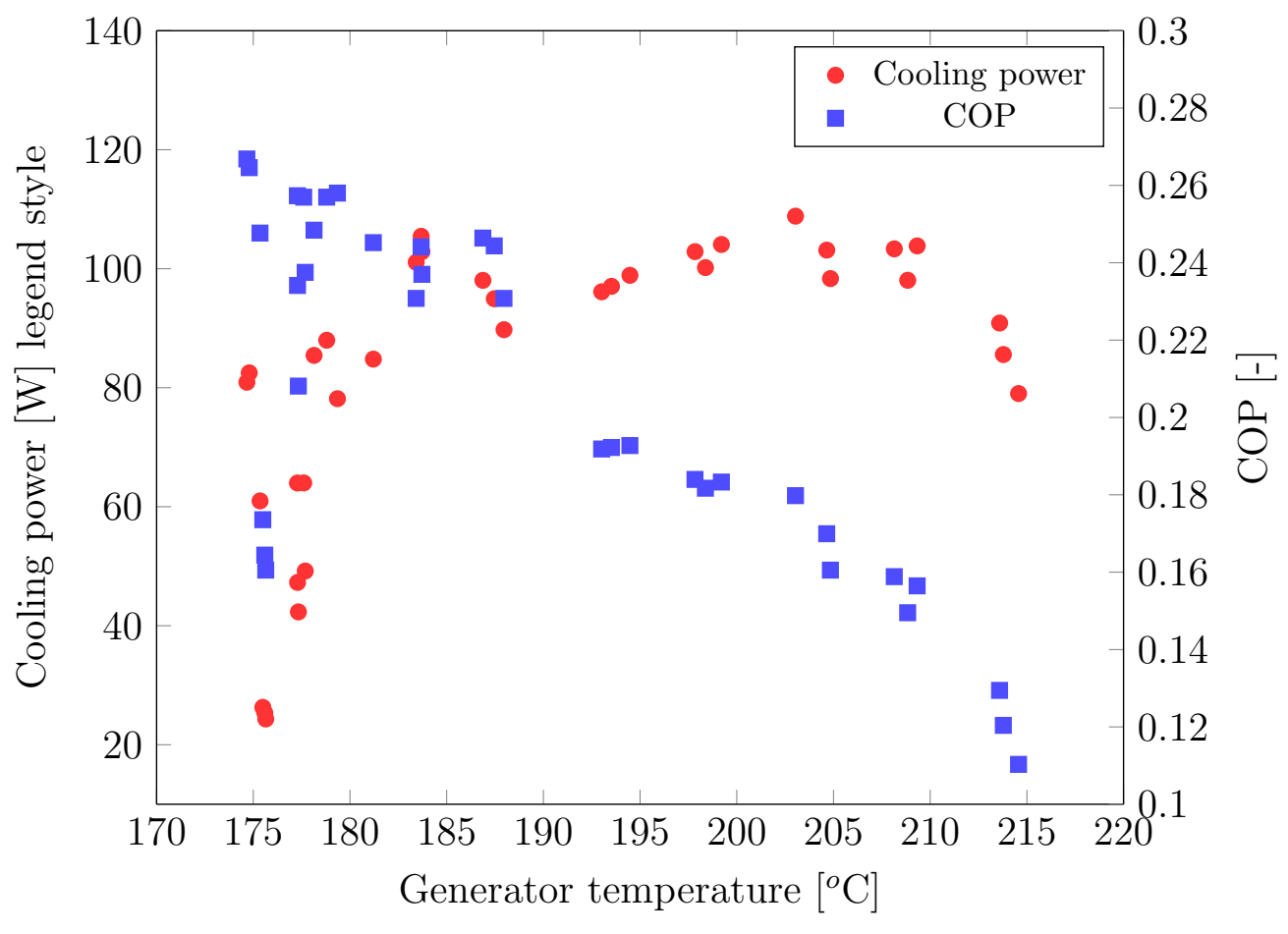

Figure 7. Experimental DAR system cooling capacity and coefficient of performance (COP) plotted against generator temperature

the experiments. The initial "cold-charge" pressure value stated by the manufacturer is $\sim 22$ bar, however it is expected that during the tests the pressure may increase by as much as 15-20\% due to the continuous supply of heat at the generator. In order to provide further corroboration of the estimated system pressure, the temperature profile along the rectifier and condenser is plotted in Fig. 8, for various values of $\dot{Q}_{\text {gen }}$. When analysing the plot, it is expected that the condensation of pure ammonia will be identifiable by an isothermal region, which should also allow the corresponding system pressure to be determined.

Starting at the lowest heat input value of $\dot{Q}_{\text {gen }}=150 \mathrm{~W}$, Fig. 8 shows an isothermal region in the serpentine and upper sections of the rectifier, occurring at a temperature of $56.5{ }^{\circ} \mathrm{C}$ and corresponding to an equivalent ammonia condensation pressure of 24 bar. That this isothermal region is observed in the rectifier rather than the condenser suggests a sub-optimal performance in which the rectifier is rejecting more heat than required for the given generator load. As $\dot{Q}_{\text {gen }}$ is raised from 150 to $350 \mathrm{~W}$, the position of the isothermal condensation region shifts from the serpentine section of the 


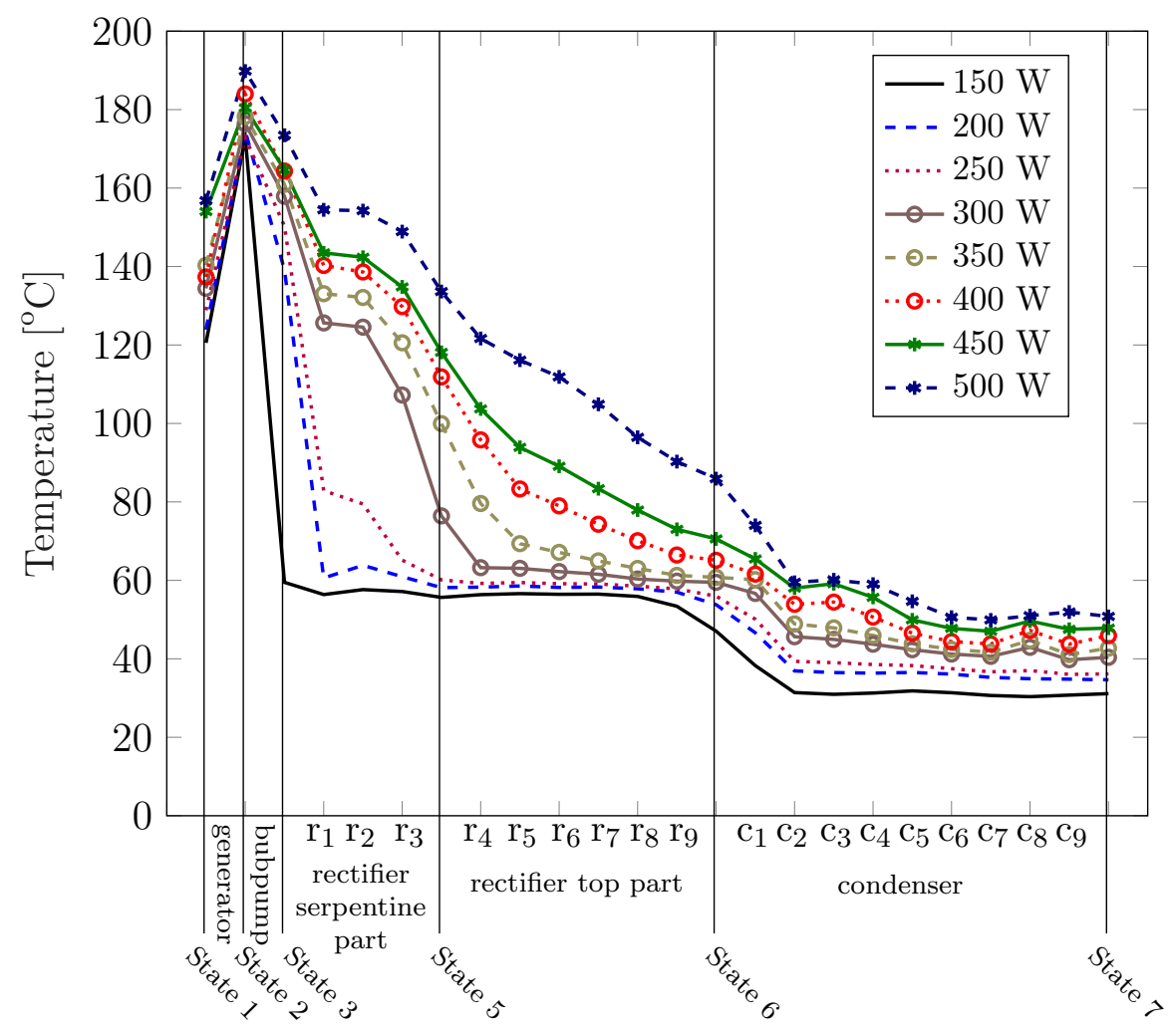

Figure 8. Temperature profile from generator inlet (State 1) to condenser outlet (State 7) for different generator power.

rectifier to the horizontal section, and eventually to the condenser. At the $350 \mathrm{~W}$ the measured condensation temperature is $61{ }^{\circ} \mathrm{C}$, corresponding to an ammonia condensation pressure of 26.8 bar. At this point a larger quantity of condensed ammonia flows by gravity toward the evaporator, where it can provide useful cooling, rather draining back to the generator/bubble pump. As $\dot{Q}_{\text {gen }}$ is increased further from 350 to $700 \mathrm{~W}$, an isothermal condensation region is less clearly defined due to the increased fraction of water vapour present in the condenser.

In Fig. 9, the ammonia concentration at the condenser inlet is estimated from the saturated vapour temperature. For low heat input conditions up to $400 \mathrm{~W}$, the temperature measured at the condenser inlet indicates a highly effective separation of water from the vapour mixture in the rectifier and a high purity refrigerant vapour $\left(y_{6}>0.998\right)$ entering the condenser. Beyond this point, the ammonia concentration $y_{6}$ decreases in exponential fashion, as the condenser inlet temperature $T_{6}$ is observed 


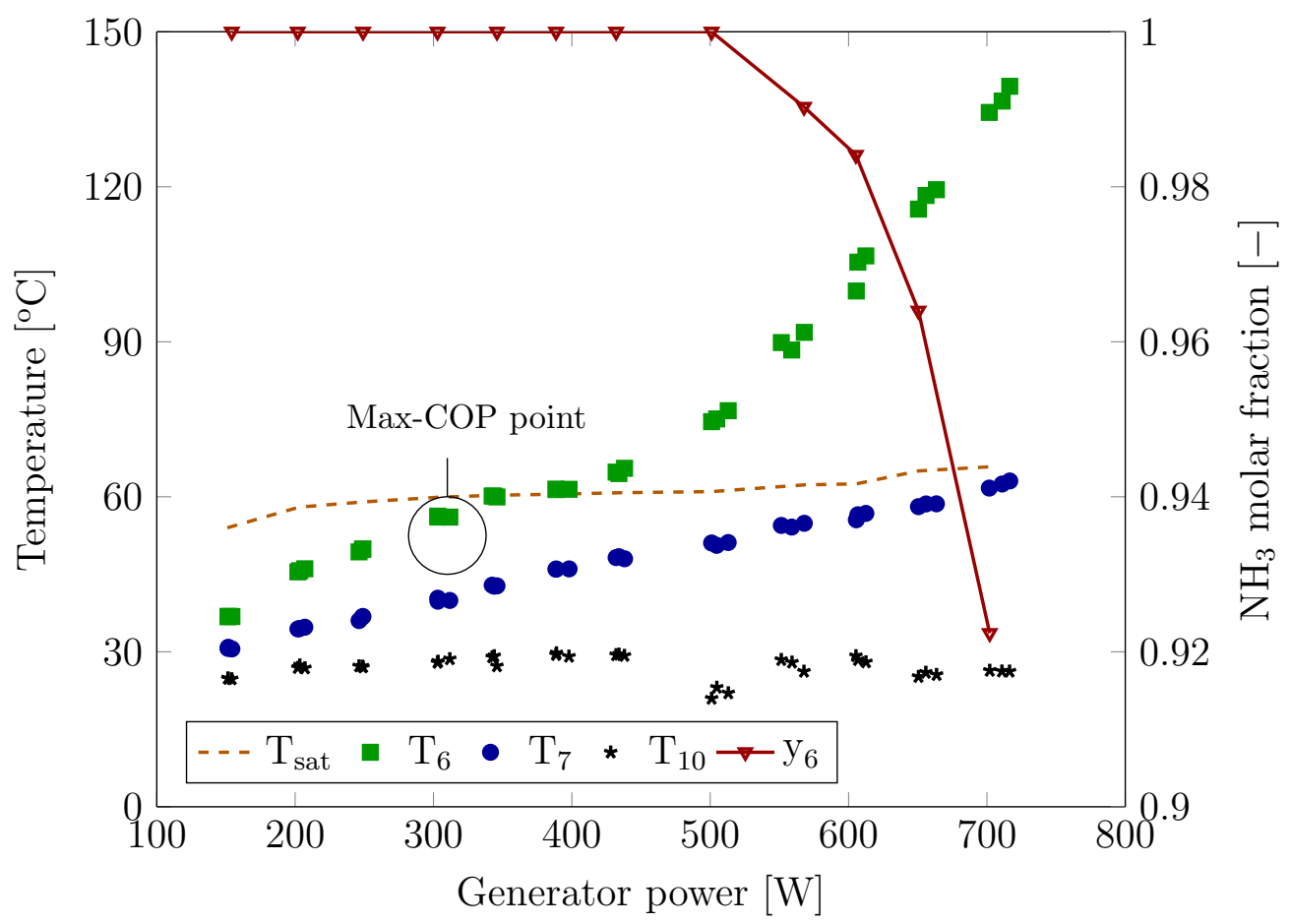

Figure 9. Condenser inlet and outlet temperatures $\left(T_{6}\right.$ and $\left.T_{7}\right)$; and estimated molar concentration the condenser inlet $\left(y_{6}\right)$. Also shown is the saturated liquid temperature corresponding to $y_{6}$.

to increase sharply. At the highest generator heat input of $700 \mathrm{~W}$, the condenser inlet temperature is $140{ }^{\circ} \mathrm{C}$ and the ammonia vapour concentration is 0.92 . The dotted line $T_{\text {sat }}$ in Fig. 9 indicates the saturated liquid temperature of the refrigerant at the estimated system pressure. The condenser outlet temperature $T_{7}$ is $3-23 \mathrm{~K}$ below the saturated liquid temperature, and shows more considerable sub-cooling of the refrigerant at lower values of $\dot{Q}_{\text {gen }}$. This observation is significant for the evaluation of the system model, in which the refrigerant is assumed to exit the condenser in a saturated liquid state, and will be discussed further in Section 3.2.

In the system model, the evaporator temperature is an important input parameter required for the calculation of the relative mass flow-rates of refrigerant and inert gas, which are highly influential on the COP of the system. In the model, State 9 represents the point at which the refrigerant and inert gas come into contact; resulting in a drop in refrigerant partial pressure and also a drop in temperature as the refrigerant begins to evaporate. A particular challenge in the experimental evaluation of this process is 


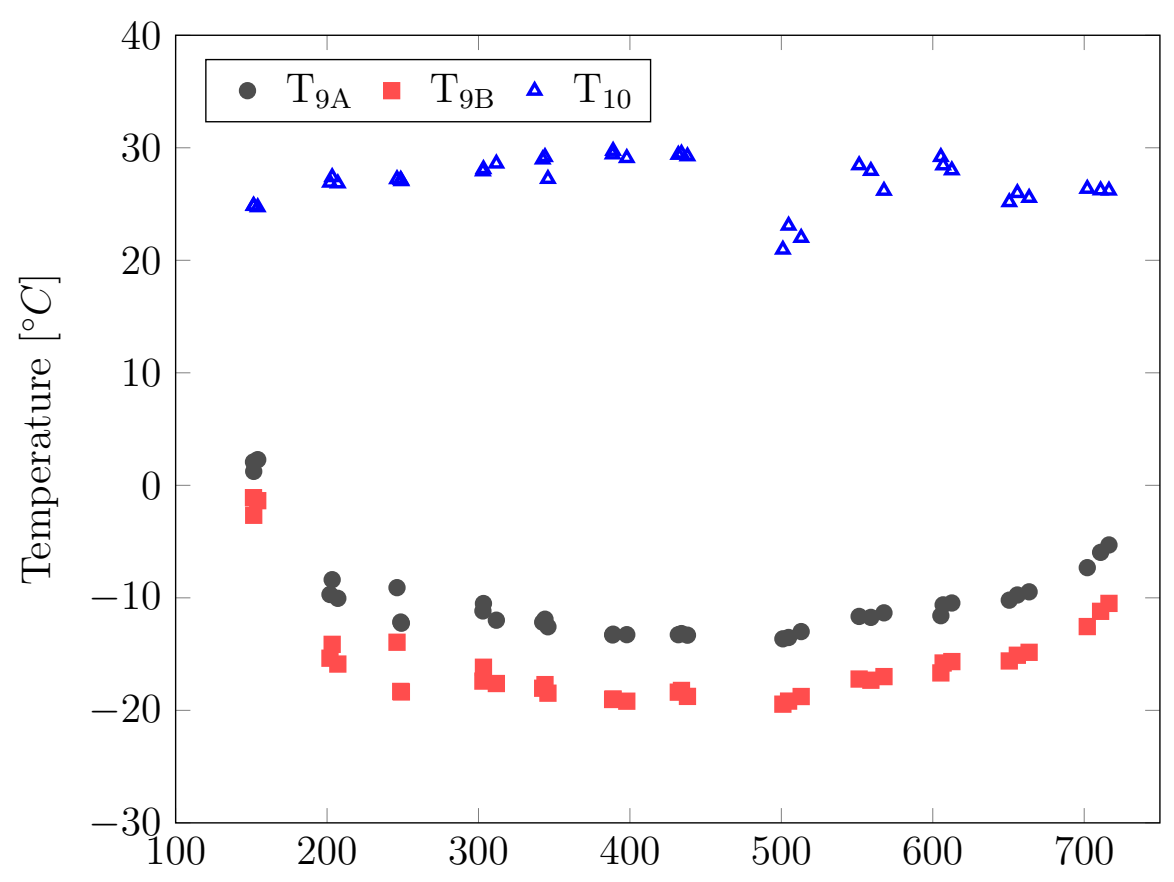

Figure 10. Temperatures measured at the evaporator inlet, upstream and downstream of the refrigerant-inert gas mixing point (States 9A and 9B, repectively), and also at the evaporator outlet (State 10). See Fig. 1 for measurement positions.

the accurate measurement of the temperature at State 9 , as a significant variation in temperature is found to occur over a relatively short distance along the top section of the evaporator. After the initial drop in temperature, which typically occurs along the first 10-20 cm of tubing, a more gradual increase in temperature occurs toward the evaporator outlet. In Fig 10, $T_{9 \mathrm{~A}}$ is the temperature measured at the point at which the refrigerant is introduced, $T_{9 \mathrm{~B}}$ is the minimum evaporator temperature measured just after the initial temperature drop and $T_{10}$ is the temperature measured at the outlet of the evaporator (the temperature measurement positions are indicated on the system diagram in Fig. 1).

In Fig. 11, $T_{8}$ is the temperature of the weak solution exiting the liquid heat exchanger (LHX) and entering the absorber, while $T_{11}$ is the temperature of the rich solution exiting the reservoir and entering the liquid solution heat exchanger (LHX). The weak solution stream is the hotter stream in the LHX, and thus it is expected that $T_{8}$ should be slightly higher than $T_{11}$, however Fig. 11 shows the opposite. A reasonable explanation is that the weak solution receives additional cooling from the ambient air 


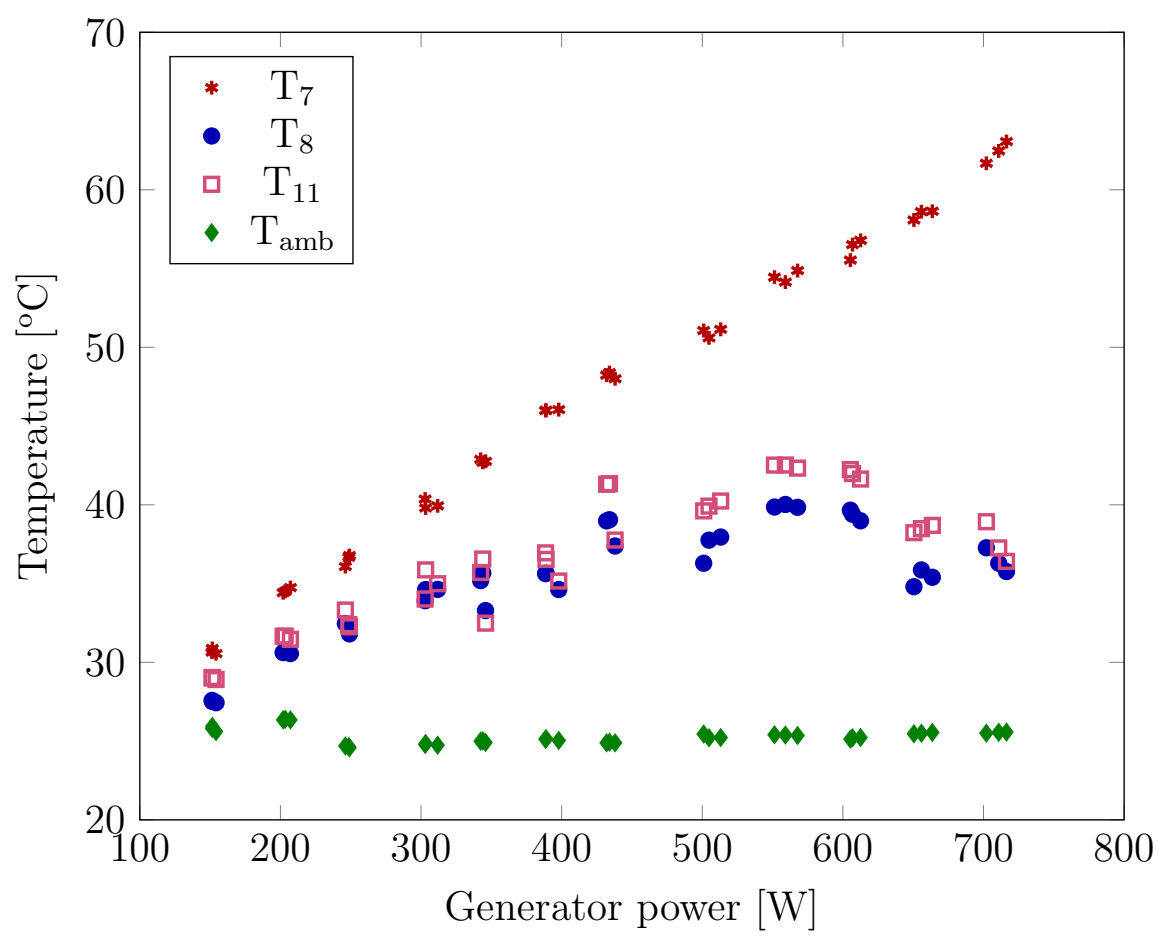

Figure 11. Temperatures at the condenser outlet (State 7), absorber inlet (State 8), and in the fluid reservoir (State 11). Also shown is the ambient temperature.

as it travels in the connecting tube between the LHX and the top of the absorber. It can also be observed that both $T_{8}$ and $T_{11}$ reach a maximum value at around $\dot{Q}_{\text {gen }}=550 \mathrm{~W}$ and then begin to decrease as $\dot{Q}_{\text {gen }}$ is increased further. This maybe due to "dry-out" in the bubble pump that interrupts the flow of weak solution to the absorber. An assumption used in the system model is that the reservoir outlet (State 11) and the condenser outlet (State 7) are at the same temperature, as both components reject heat to the ambient air. Figure 11 shows that this assumption becomes less valid at higher values of $\dot{Q}_{\text {gen }}$, as the required cooling duty from the condenser becomes too large for sufficient heat to be rejected to the ambient air.

\subsection{Model evaluation}

Performance calculations were performed using the DAR system model for the range of generator heat inputs tested in the experimental investigation. The input parameters $T_{1}, T_{2}, T_{3}, T_{6}$, and $T_{10}$ were also set to the values measured in the experiments. The system pressure was set to the estimate values obtained from the analysis 
of Fig. 8. In order to evaluate the various assumptions used in the system model (see Section 2.4), five variants of the model are investigated:

- Basic model: all of the default model assumptions presented in Section 2.4 are applied.

- Isothermal bubble pump: heat losses from the bubble pump are neglected by setting $T_{3}=T_{2}$ and $\dot{Q}_{\text {loss }}=0$.

- Condenser subcooling: subcooling at the condenser outlet is taken into account by specifying the temperature at State 7 as a model input parameter based on the experimental data, rather than using the default assumption of a saturated liquid state.

- Lower reservoir temperature: the temperature at State 11 is specified as a model input parameter based on the experimental data, rather than using the default assumption $T_{11}=T_{7}$.

- Weak solution pre-cooling: additional heat losses from the weak solution to the ambient along the connecting tube between the LHX and the absorber inlet are considered by specifying the temperature at State 8 as a model input parameter based on the experimental data, rather than solving as an output of the LHX energy balance.

The input data used for each of the model variants is shown in Table 1. The model predictions are compared to the experimental data in terms of cooling output $\left(\dot{Q}_{\text {evap }}\right)$ in Fig. 12 and COP in Fig. 13, and the model output data is summarised in Table 2. The basic model is shown to under-predict the cooling output from the DAR system across the full range of generator heat input values, but provides a reasonably close agreement with the experimental data around the nominal design point of the system, predicting $\dot{Q}_{\text {evap }}$ to within 10-13\% at values of $\dot{Q}_{\text {gen }}$ between $350-400 \mathrm{~W}$. It should be noted here that the steady-state system model is not expected to fully capture some of the more complex phenomena that occur under off-design conditions, such as the unsteady behaviour due to dry-out in the bubble pump at high heat loads. With this in mind, it is notable that the basic model only predicts net cooling delivered from the evaporator at values of $\dot{Q}_{\text {gen }}$ between $250-530 \mathrm{~W}$. At the lowest values of $\dot{Q}_{\text {gen }}$, the predicted mass flow-rate of refrigerant proceeding from the rectifier to the condenser is 
Table 1. Input parameters used in the DAR system model variants, based on experimental data and the stated assumptions of each model variant.

\begin{tabular}{lcccc}
\hline & & \multicolumn{3}{c}{ Basic model inputs } \\
\cline { 3 - 5 }$\dot{Q}_{\text {gen }}$ & $\mathrm{W}$ & 300 & 400 & 500 \\
$p$ & $\mathrm{bar}$ & 26.1 & 26.5 & 26.8 \\
$T_{1}$ & ${ }^{\circ} \mathrm{C}$ & 137.3 & 147.0 & 153.0 \\
$T_{2}$ & ${ }^{\circ} \mathrm{C}$ & 176.0 & 181.2 & 188.7 \\
$T_{3}$ & ${ }^{\circ} \mathrm{C}$ & 148.7 & 167.9 & 172.9 \\
$T_{6}$ & ${ }^{\circ} \mathrm{C}$ & 51.4 & 62.6 & 79.0 \\
$T_{10}$ & ${ }^{\circ} \mathrm{C}$ & 28.6 & 29.0 & 28.8 \\
\hline & & & Modified or additional inputs \\
$T_{3}{ }^{(i)}$ & ${ }^{\circ} \mathrm{C}$ & 176.0 & 181.2 & 188.7 \\
$T_{7}{ }^{(i i)}$ & ${ }^{\circ} \mathrm{C}$ & 39.8 & 45.2 & 50.6 \\
$T_{8}{ }^{(i i i)}$ & ${ }^{\circ} \mathrm{C}$ & 31.2 & 33.2 & 34.1 \\
$T_{11}{ }^{(i v)}$ & ${ }^{\circ} \mathrm{C}$ & 36.1 & 39.0 & 40.6 \\
\hline
\end{tabular}

(i) Modified input used in "Isothermal bubble pump" model.

(ii) Additional input used in "Condenser subcooling" model.

(iii) Additional input used in "Weak solution pre-cooling" model.

(iv) Additional input used in "Lower reservoir temperature" model.

too low to produce useful cooling from the evaporator in the model. Meanwhile, at the highest values of $\dot{Q}_{\text {gen }}$, the larger predicted fraction of water entering the evaporator also results in no useful cooling output in the model due to a lower predicted partial pressure of refrigerant and a higher mass fraction of inert gas.

The "isothermal bubble pump" model is shown to predict a higher cooling output at lower values of $\dot{Q}_{\text {gen }}$, because the higher temperature at the bubble-pump outlet results in a larger mass flow-rate of refrigerant at the rectifier outlet. In fact this model over-predicts the cooling output from the system by as much as $50 \%$ at the lowest heat input conditions, suggesting that some heat is indeed dissipated to the environment in the bubble pump, but that the quantity of dissipated heat is overestimated in the 


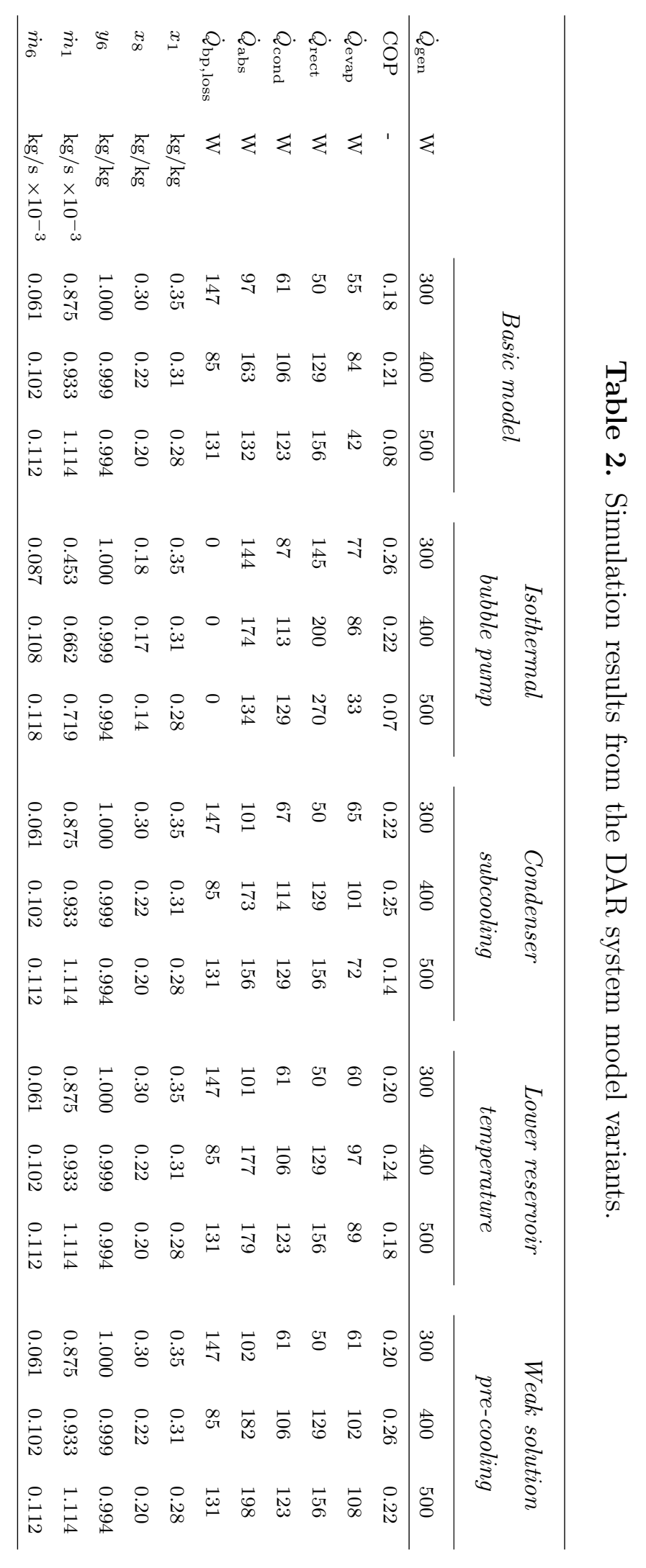




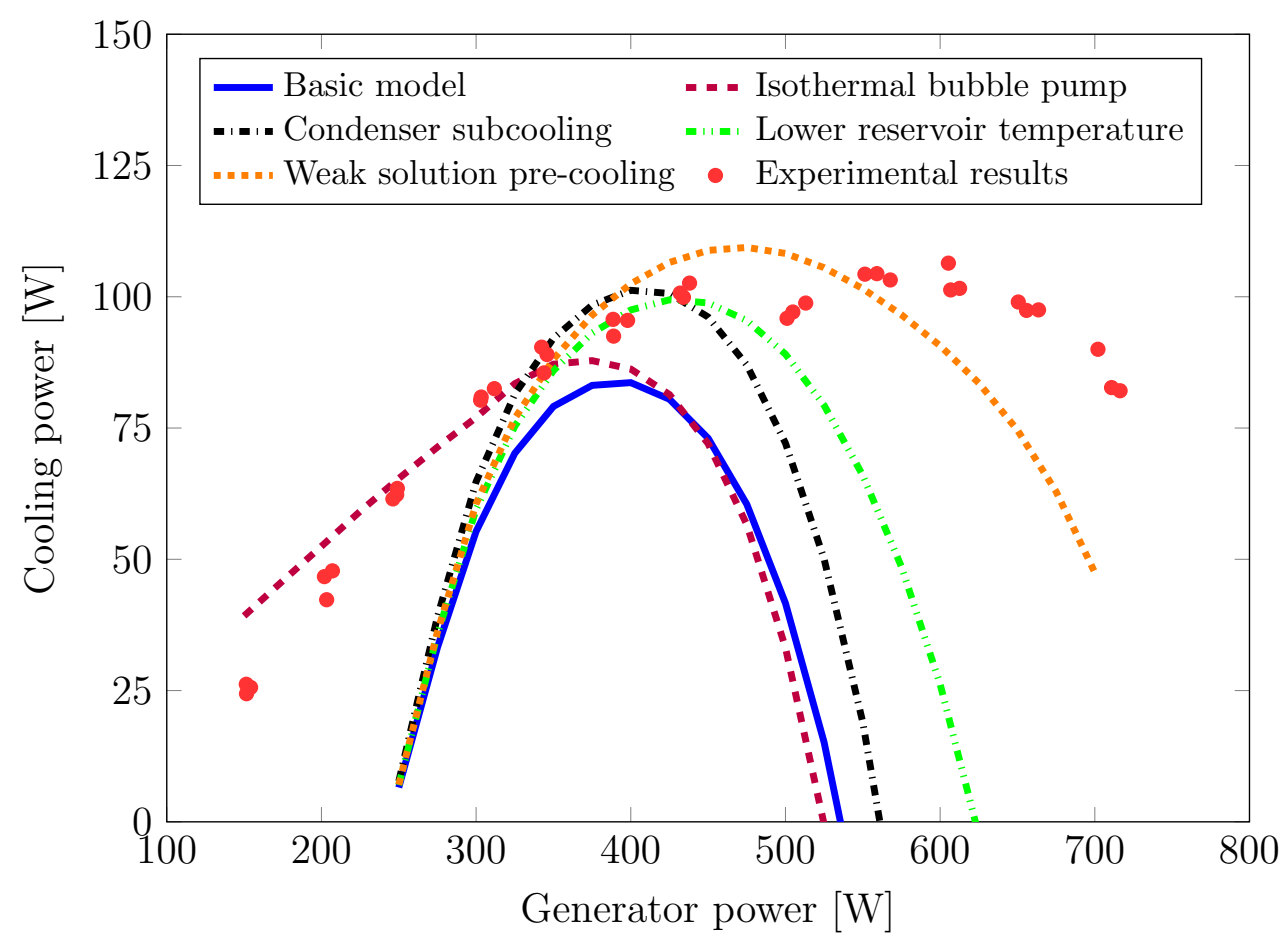

Figure 12. DAR system cooling capacity plotted against generator heat input. Comparison of the steady-state thermodynamic model predictions (under various input assumptions) and the experimental results.

basic model. It should also be noted that the predicted mass flow-rate of refrigerant vapour entering the condenser at State 6 is highly dependent on the assumption of vapour-liquid equilibrium between States 4 and 5 in the rectifier.

The result of modifying the model to include the subcooing at the condenser outlet (in the "condenser subcooling" variant) is a 20-50\% increase in cooling output relative to the basic model across most of the operating range, due partly to the significantly lower temperature of refrigerant entering the evaporator/GHX. The temperatures in the absorber and reservoir are also reduced due to the default model assumption that $T_{11}=T_{7}$, and this further contributes to increased cooling output. At the nominal design point of the system this variant of the model provides a slight over-prediction of the system performance compared to the experimental results. Similarly, when the reservoir temperature is provided as an explicit input to the model in the "lower reservoir temperature" variant, the energy balances in the absorber and LHX are also affected, resulting in a lower temperature of inert gas returning to the evaporator and 


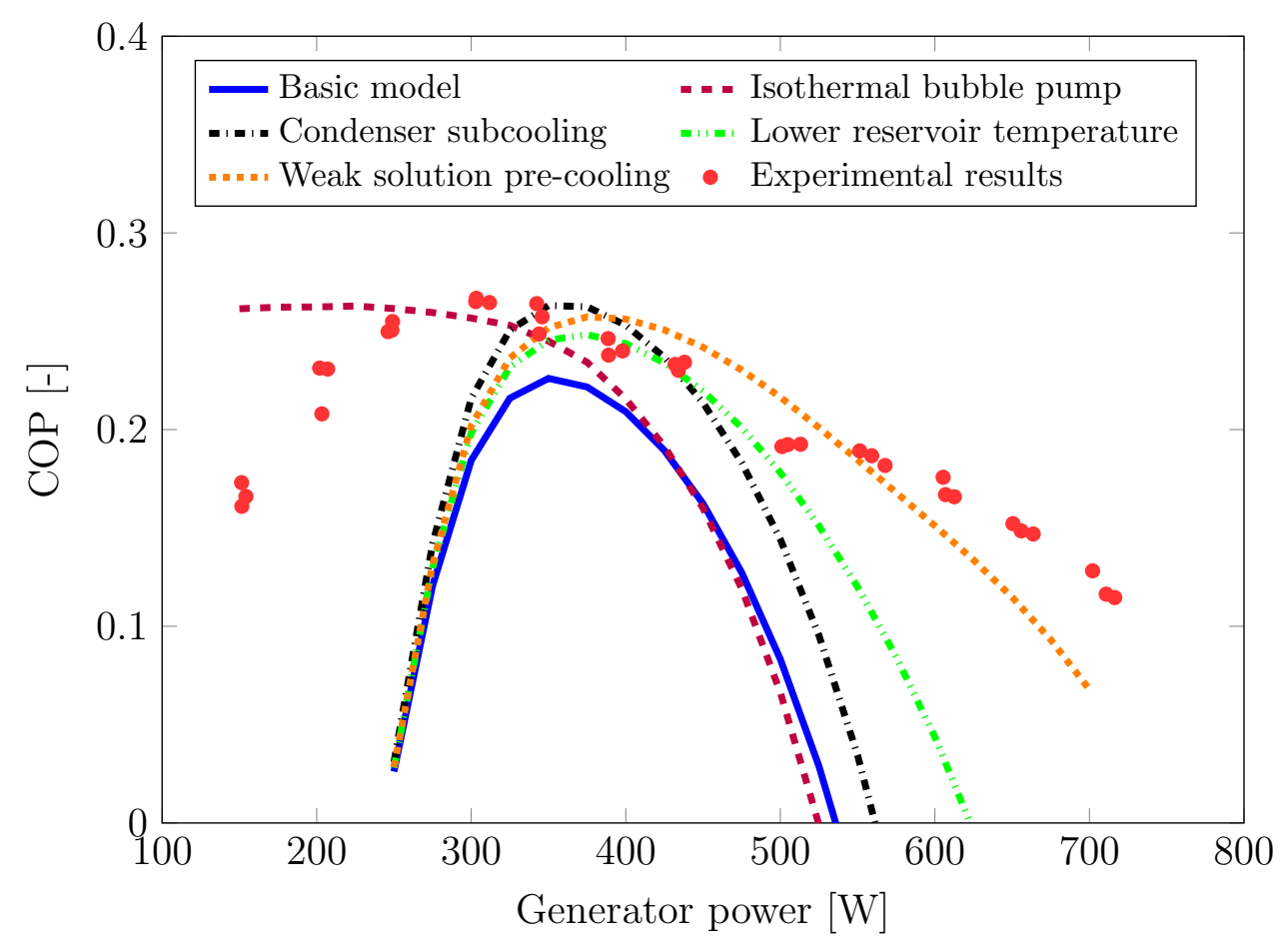

Figure 13. DAR system COP plotted against generator heat input. Comparison of the steady-state thermodynamic model predictions (under various input assumptions) and the experimental results.

thus resulting in a higher cooling output relative to the basic model. This also results in an extended operating range, with useful cooling predicted at values of $\dot{Q}_{\text {gen }}>600 \mathrm{~W}$. For the model in which the "weak solution pre-cooling" is taken into account, the temperatures in the absorber are also affected, and the temperature of the inert gas entering the GHX is reduced to an even larger extent. This model variant provides the best prediction of the cooling output at the high end of the operating range, but still under-predicts $\dot{Q}_{\text {evap }}$ by as much as $50 \%$ at the highest values of $\dot{Q}_{\text {gen }}$.

\section{Conclusion}

In this study, a detailed experimental investigation was conducted to analyse the performance of a newly-developed ammonia-water diffusion absorption refrigeration (DAR) unit over a range of heat-supply conditions. Electrical cartridge heaters were used to provide thermal input to the system which was varied in the range 150-700 W 
(resulting in generator temperatures measured in the range $175-215{ }^{\circ} \mathrm{C}$ ), while the refrigerated space surrounding the evaporator was maintained at a fixed temperature of $25{ }^{\circ} \mathrm{C}$. The results of the experiments were compared to the predictions of a simple steady-state thermodynamic model of the DAR cycle and used to evaluate a number of simplifying assumptions used in that model.

The experimental results have demonstrated that the cooling COP is limited by the geometry of the system, peaking at a value of 0.26 corresponding to a heat input of $300 \mathrm{~W}$ and a cooling output of $80 \mathrm{~W}$. The cooling capacity continues to increase as generator heat input is further increased, reaching a maximum value of $\sim 100 \mathrm{~W}$ before eventually declining. At heat input conditions higher than $500 \mathrm{~W}$, higher temperatures in the bubble pump indicated possible dry-out due to over-heating of the generator.

The findings have indicated that a simple thermodynamic model, such as the one used to analyse the experimental results, can provide reasonable estimates of the DAR cooling output close to the design point of the system (i.e. where thermal input load is set to provide maximum-COP operation). The basic model has been shown to predict cooling capacity to within $\sim 10 \%$ at the design point, while the prediction was improved to within $2 \%$ by accounting for the considerable degree of subcooling in the condenser that was observed in the experiments. Model variants were developed to interrogate the assumptions for components such as the bubble pump, reservoir and solution heat exchanger. Despite some promising agreement of the predicted performance with experimental data over limited ranges of conditions, these variants were not able to predict the cooling output accurately over the full operating range.

Thus, this study has demonstrated that in order to predict the performance of the system with variable heat sources such as solar-thermal energy, the off-design performance of the system requires further investigation. A reliable part-load model would be an invaluable tool for the investigation of alternative working fluid mixtures that may be better-suited to DAR operation with low-cost (low temperature) solar collectors, providing optimal cooling output over a range of diurnal or seasonal solar irradiance conditions. Future work should focus on the development of an improved model capable of predicting the part-load/off-design behaviour of ammonia-water-hydrogen DAR systems through detailed understanding of the physical phenomena in the various system components. This is a challenging proposition due to the passive nature of the system operation, and in particular the lack of control over the system flow-rates. In order to validate such a model, further experimental work is also required to map the system 
performance across a wide range of charge pressures and mixture concentrations.

\section{Acknowledgement}

This work was supported by the the Islamic Development Bank and the UK Engineering and Physical Sciences Research Council (EPSRC) [grant numbers EP/P004709/1, EP/M025012/1, and EP/P030920/1]. The authors would also like to gratefully acknowledge the contributions of Robert Edwards and Michael Reid from Solar-Polar Ltd. Data supporting this publication can be obtained on request from cep-lab@imperial.ac.uk.

\section{References}

[1] International Energy Agency. The future of cooling: Opportunities for energy-efficient air conditioning; 2018.

[2] Sivak M. Potential energy demand for cooling in the 50 largest metropolitan areas of the world: implications for developing countries. Energy Policy. 2009;37(4):1382-1384.

[3] Santamouris M. Cooling the buildings-past, present and future. Energy and Buildings. 2016;128:617-638.

[4] Masanet E, Poponi D, Bryant T, Burnard K, Cazzola P, Dulac J, et al. Energy technology perspectives 2016 - towards sustainable urban energy systems. International Energy Agency; 2016.

[5] Ramos A, Chatzopoulou MA, Guarracino I, Freeman J, Markides CN. Hybrid photovoltaicthermal solar systems for combined heating, cooling and power provision in the urban environment. Energy Conversion and Management. 2017;150:838-850.

[6] Freeman J, Klaus H, Markides C. An assessment of solar-powered organic rankine cycle systems for combined heating and power in UK domestic applications. Applied Energy. 2015;138:605 620 .

[7] Wang Y, Li M, Ji X, Yu Q, Li G, Ma X. Experimental study of the effect of enhanced mass transfer on the performance improvement of a solar-driven adsorption refrigeration system. Applied Energy. 2018;224:417-425.

[8] Golparvar B, Niazmand H, Sharafian A, Hosseini AA. Optimum fin spacing of finned tube adsorber bed heat exchangers in an exhaust gas-driven adsorption cooling system. Applied Energy. 2018;232:504-516.

[9] Choudhury B, Saha BB, Chatterjee PK, Sarkar JP. An overview of developments in adsorption refrigeration systems towards a sustainable way of cooling. Applied Energy. 2013;104:554-567.

[10] Saha B, Akisawa A, Kashiwagi T. Solar/waste heat driven two-stage adsorption chiller: the prototype. Renewable Energy. 2001;23(1):93-101.

[11] Wang D, Zhang J, Yang Q, Li N, Sumathy K. Study of adsorption characteristics in silica gel-water adsorption refrigeration. Applied Energy. 2014;113:734-741. 
[12] Youssef PG, Mahmoud SM, Al-Dadah RK. Performance analysis of four bed adsorption water desalination/refrigeration system, comparison of AQSOA-Z02 to silica-gel. Desalination. 2015;375:100-107.

[13] Du S, Li X, Yuan Z, Du C, Wang W, Liu Z. Performance of solar adsorption refrigeration in system of SAPO-34 and ZSM-5 zeolite. Solar Energy. 2016;138:98-104.

[14] Sadeghlu A, Yari M, Mahmoudi S, Dizaji HB. Performance evaluation of zeolite 13X/CaCl2 twobed adsorption refrigeration system. International Journal of Thermal Sciences. 2014;80:76-82.

[15] Tokarev MM, Gordeeva LG, Grekova AD, Aristov YI. Adsorption cycle "heat from cold" for upgrading the ambient heat: the testing a lab-scale prototype with the composite sorbent CaClBr/silica. Applied Energy. 2018;211:136-145.

[16] Milazzo A, Mazzelli F. Future perspectives in ejector refrigeration. Applied Thermal Engineering. 2017;121:344-350.

[17] Chen W, Shi C, Zhang S, Chen H, Chong D, Yan J. Theoretical analysis of ejector refrigeration system performance under overall modes. Applied Energy. 2017;185:2074-2084.

[18] Tashtoush BM, Al-Nimr M, Khasawneh MA. Investigation of the use of nano-refrigerants to enhance the performance of an ejector refrigeration system. Applied Energy. 2017;206:14461463.

[19] Aligolzadeh F, Hakkaki-Fard A. A novel methodology for designing a multi-ejector refrigeration system. Applied Thermal Engineering. 2019;151:26-37.

[20] Chunnanond K, Aphornratana S. Ejectors: applications in refrigeration technology. Renewable and Sustainable Energy Reviews. 2004;8(2):129-155.

[21] International Energy Agency- Solar Heating and Cooling. Technology and quality assurance for solar thermal cooling systems; 2015.

[22] Assilzadeh F, Kalogirou SA, Ali Y, Sopian K. Simulation and optimization of a LiBr solar absorption cooling system with evacuated tube collectors. Renewable Energy. 2005;30(8):11431159.

[23] Florides GA, Kalogirou SA, Tassou SA, Wrobel L. Design and construction of a LiBr-water absorption machine. Energy Conversion and Management. 2003;44(15):2483-2508.

[24] Yuan H, Sun P, Zhang J, Sun K, Mei N, Zhou P. Theoretical and experimental investigation of an absorption refrigeration and pre-desalination system for marine engine exhaust gas heat recovery. Applied Thermal Engineering. 2019;150:224-236.

[25] Takalkar GD, Bhosale RR, Mali NA, Bhagwat SS. Thermodynamic analysis of EMISE-water as a working pair for absorption refrigeration system. Applied Thermal Engineering. 2019;148:787795.

[26] Ruiz E, Ferro V, De Riva J, Moreno D, Palomar J. Evaluation of ionic liquids as absorbents for ammonia absorption refrigeration cycles using COSMO-based process simulations. Applied Energy. 2014;123:281-291.

[27] Herold KE, Radermacher R, Klein SA. Absorption chillers and heat pumps. CRC press; 2016.

[28] Von Platen BC, Munters CG. Refrigerator; 1925. US patent US1685764A.

[29] Sayadi Z, Thameur NB, Bourouis M, Bellagi A. Performance optimisation of solar driven smallcooled absorption-diffusion chiller working with light hydrocarbons. Energy Conversion and Management. 2013;74:299-307.

[30] Yildiz A. Thermoeconomic analysis of diffusion absorption refrigeration systems. Applied Ther- 
mal Engineering. 2016;99:23-31.

[31] Munters CG, Von Platen BC. Refrigerator; 1925. US patent US1799201A.

[32] Najjaran A, Freeman J, Ramos A, Markides CN. Experimental performance analysis of an ammonia-water diffusion absorption refrigeration cycle. In: $13^{\text {th }}$ International Conference on Heat Transfer, Fluid Mechanics and Thermodynamics. Portoroz̃, Slovenia; 2017. p. 951-955.

[33] Najjaran-Kheirabadi A, Freeman J, Cabal AR, Markides CN. Experimental investigation of an Ammonia-Water diffusion-absorption refrigerator (DAR) at part load. In: ASME 2017 Heat Transfer Summer Conference. vol. 1; 2017. p. V001T09A004.

[34] Harraz AA, Freeman J, Wang K, Mac Dowell N, Markides CN. Diffusion-absorption refrigeration cycle simulations in gPROMS using SAFT- $\gamma$ Mie. Energy Procedia. 2019;158:2360-2365.

[35] Gurevich B, Jelinek M, Levy A, Borde I. Performance of a set of parallel bubble pumps operating with a binary solution of R134a-DMAC. Applied Thermal Engineering. 2015;75:724-730.

[36] Mazouz S, Mansouri R, Bellagi A. Experimental and thermodynamic investigation of an ammonia/water diffusion absorption machine. International Journal of Refrigeration. 2014;45:83-91.

[37] Zohar A, Jelinek M, Levy A, Borde I. Performance of diffusion absorption refrigeration cycle with organic working fluids. International Journal of Refrigeration. 2009;32(6):1241-1246.

[38] Acuña A, Velázquez N, Cerezo J. Energy analysis of a diffusion absorption cooling system using lithium nitrate, sodium thiocyanate and water as absorbent substances and ammonia as the refrigerant. Applied Thermal Engineering. 2013;51(1):1273-1281.

[39] Rattner AS, Garimella S. Coupling-fluid heated bubble pump generators: experiments and model development. Science and Technology for the Built Environment. 2015;21(3):332-347.

[40] Rattner AS, Garimella S. Low-source-temperature diffusion absorption refrigeration. part I: modeling and cycle analysis. International Journal of Refrigeration. 2016;65:287-311.

[41] Rattner AS, Garimella S. Low-source-temperature diffusion absorption refrigeration. part II: experiments and model assessment. International Journal of Refrigeration. 2016;65:312-329.

[42] Zohar A, Jelinek M, Levy A, Borde I. The influence of diffusion absorption refrigeration cycle configuration on the performance. Applied Thermal Engineering. 2007;27(13):2213-2219.

[43] Zohar A, Jelinek M, Levy A, Borde I. The influence of the generator and bubble pump configuration on the performance of diffusion absorption refrigeration (DAR) system. International Journal of Refrigeration. 2008;31(6):962-969.

[44] Vicatos G, Bennett A. Multiple lift tube pumps boost refrigeration capacity in absorption plants. Journal of Energy in Southern Africa. 2017;18(4):49-57.

[45] Jakob U, Eicker U, Schneider D, Taki A, Cook M. Simulation and experimental investigation into diffusion absorption cooling machines for air-conditioning applications. Applied Thermal Engineering. 2008;28(10):1138-1150.

[46] Starace G, De Pascalis L. An advanced analytical model of the diffusion absorption refrigerator cycle. International Journal of Refrigeration. 2012;35(3):605-612.

[47] Patek J, Klomfar J. Simple functions for fast calculations of selected thermodynamic properties of the ammonia-water system. International Journal of Refrigeration. 1995;18(4):228-234.

[48] Zohar A, Jelinek M, Levy A, Borde I. Numerical investigation of a diffusion absorption refrigeration cycle. International Journal of Refrigeration. 2005;28(4):515-525. 